\title{
Primary hyperparathyroidism: epidemiology, clinical features, diagnostic tools and current management
}

\author{
Andrea Percivale, ${ }^{1}$ Paola Gnerre, ${ }^{2}$ Giulio Damonte, ${ }^{2}$ Sandra Buscaglia, ${ }^{2}$ Mario Monachesi,${ }^{2}$ Lionello Parodi, ${ }^{2}$ \\ Rodolfo Tassara, ${ }^{2}$ Gianluca Curletti, ${ }^{3}$ Giovanni Saccomani ${ }^{1}$ \\ ${ }^{1}$ Department of Surgery, Santa Corona Hospital, Pietra Ligure (SV); ${ }^{2}$ Department of Internal Medicine, San Paolo Hospital, \\ Savona; ${ }^{3}$ Department of Surgery, University of Genova, Genova, Italy
}

\begin{abstract}
Primary hyperparathyroidism (PHPT) is a clinical condition characterized by overactive parathyroid gland secretion of parathyroid hormone with concurrent alteration of the phosphocalcemic metabolism. We present a literature review on primary hyperparathyroidism addressing key on clinical presentation, causes, medical and surgical treatment at the best of our knowledge. Based on this review we confirm the role of serum calcium and serum level examination, as well as we define the definitive treatment for PHPT being parathyroidectomy. In case of contraindication for surgery, medical treatment can play a relevant role.
\end{abstract}

\section{Introduction}

Primary hyperparathyroidism (PHPT) is a disease caused by overactive secretion of parathyroid hormone (PTH) with a concurrent alteration of the phosphocalcemic metabolism: commonly we found an association between hypercalcemic status and elevated PTH plasma levels or not properly normal. Widespread screening of serum calcium introduced in the 70's has made PHPT a relatively common disease: in these cases hypercalcemia is quickly diagnosed and in the western world the disease tends to appear with not specific symptoms such as fatigue mood disturbance and cognitive impairments. ${ }^{1}$ The main cause is represented by a solitary parathyroid adenoma (80-85\% of cases) (Figure 1): the remaining $15-20 \%$ of cases are represented by conditions of dif-

\footnotetext{
Correspondence: Paola Gnerre, Department of Internal Medicine, San Paolo Hospital, via Genova 1, 17100 Savona, Italy. Tel.: +39.019.8404358 - Fax: +39.019 .8404583 .

E-mail: pgnerre@yahoo.it

Key words: Primary hyperparathyroidism; parathyroidectomy; hypercalcemic status.

Received for publication: 3 October 2014.

Revision received: 12 January 2015.

Accepted for publication: 7 February 2015.

This work is licensed under a Creative Commons Attribution NonCommercial 3.0 License (CC BY-NC 3.0).

(C) Copyright A. Percivale et al., 2015

Licensee PAGEPress, Italy

Italian Journal of Medicine 2015; 9:330-345

doi:10.4081/itjm.2015.547
}

fuse glandular hyperplasia (Figure 2) and multiple adenomas. A small percentage of patients presents with typical familial forms of multiple endocrine neoplasia type 1 (MEN 1) and multiple endocrine neoplasia type 2 (MEN 2) syndromes., ${ }^{2,3}$ Primary hyperparathyroidism generally occurs with higher rate in a population older than 55 years: it occurs 2-3 times more frequently in women than in men and has a higher prevalence in postmenopausal women. Approximately $80 \%$ of patients with PHPT are asymptomatic being the asymptomatic hypercalcemic form the most representative: signs and symptoms, when present, are due to prolonged hypercalcemic status than to elevate serum levels of PTH. ${ }^{4,5}$ The clinical manifestation remains variable ranging from the normocalcemic to the hypercalcemic PHPT form. ${ }^{6,7}$

\section{Methods of research}

A systematic literature search conducted on PubMed/Medline, Embase, Science Citation Index Expanded (SciSearch), Scopus and Cochrane Databases was done including articles cited up between $1^{\text {st }}$ August 2004 and $1^{\text {st }}$ August 2014. Guidelines from the Fourth International Workshop on Primary Hyperparathyroidism, the American Association of Clinical Endocrinologist and the American Association of Endocrine Surgeons (AACE/AAES) position statement on the Diagnosis and Management of Primary Hyperparathyroidism, guidelines from the Parathyroid Task Group of the European Association of Nuclear Medicine (EANM) and finally the National Institute of Health (NIH) guidelines and the National Endocrine and Metabolic Disease Information Service (NEMDIS) guidelines were reviewed. The research included guidelines and position statement available 
on the web site of the Italian Society of Endocrine Surgery (SIEC), Italian Society of Endocrinology (SIE), European Society of Endocrinology (ESE), Society for Endocrinology and finally AACE and AAES. Key words were entered in both British English and American English. We matched primary hyperparathyroidism with etiology, diagnosis, clinical manifestation, imaging procedures, indication for surgery, role of intraoperative serum PTH measurement and finally medical treatment: a computer link program was then used in order to exclude duplicate articles. The search strategy would be sensitive, intentionally and retrieves more articles than those required: matching the key words we found 512 published papers relevant to our study. Again for each key words category, the published papers that did not ensure the issue of our work were further omitted. The exclusion criteria applied regard articles not published in English, editorials, letters and opinion articles: we excluded articles on secondary and tertiary hyperparathyroidism not fulfilling our intent. We also excluded articles for which full publication or at least summary publication was unobtainable. Exclusion cri- teria left 143 original articles for our review: we listed references in order of appearance in the test.

\section{Epidemiology and etiology}

PHPT represents a common endocrine disease mostly in those countries in which screening is routinely done: since the early 70 's the introduction of the serum biochemical screening markedly increased the incidence and prevalence of the disease. ${ }^{8,9}$ PHPT occurs more commonly in women and the onset before 50 years of age is rare. In postmenopausal age the relationship between man and woman changes from 1:3 to $1: 5$. The various case studies worldwide show an annual incidence of 20 cases per 100,000 people with an estimated prevalence in the general population of $0.5 \%$ to $1 \%$ increasing with age over $2 \%$ in both sexes. ${ }^{10-12}$ Solitary parathyroid adenoma represents about $80 \%$ of cases of PHPT: other cases are represented by diffuse hyperplasia and multiple adenomas. About $10 \%$ of cases is represented by familial hyperparathyroidism syndrome in which multiple gland dis-

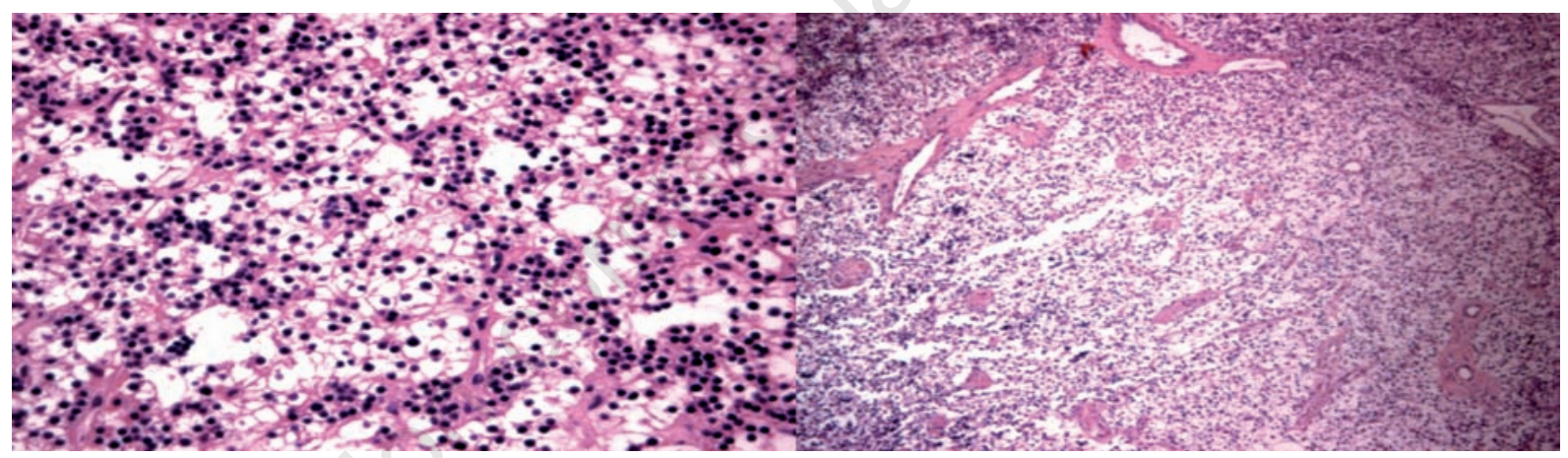

Figure 1. Parathyroid adenoma finding: polyhedral cells with marked vacuolation of the cytoplasm. The cells show minimal atypia with proliferation index MIB 1/Ki67+ $2 \%$. Honeycomb appearance is attributable to accumulation of glycogen.

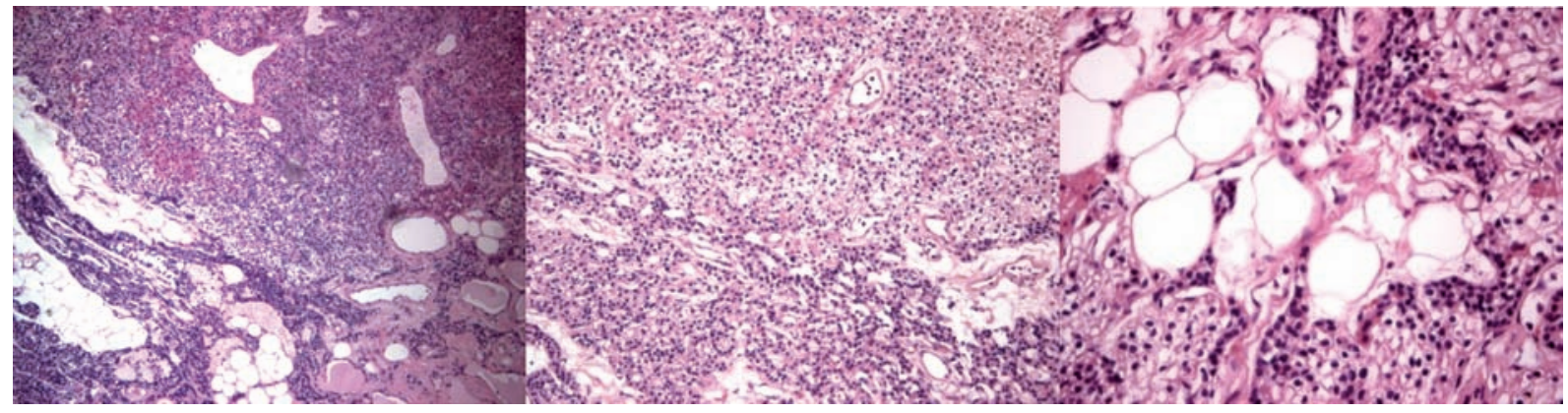

Figure 2. Diffuse chief cells hyperplasia: gland with nodular configuration, with abundant fat both in adipocytes and in the cytoplasm of parathyroid cells. In contrast in the adenoma the cells are usually devoid of droplets of intracytoplasmic neutral lipid. 
ease is the common finding. ${ }^{13-15}$ Parathyroid carcinoma is a rare disease and affects less than $10 \%$ of the forms of PHPT. ${ }^{16-18}$ There are other clinical conditions associated with familial PHPT represented by MEN 1 and MEN 2 syndromes, hyperparathyroidism-jaw tumor syndrome and isolated familial hyperparathyroidism (Table 1). PHPT represents the most common disorders in MEN 1 syndrome: it is virtually present in $100 \%$ of elderly patients affected by MEN 1 syndrome (older than 80 years) and it represents the first sign of the disease in younger patients. Regarding MEN 2A the prevalence of PHPT is lower and occurs in $20-25 \%$ of cases. ${ }^{19-21}$ The rare hyperparathyroidism jaw tumor syndrome emerges when PHPT occurs associated with jaw-bone tumors and it is caused by germline gross deletion or point mutation of selected gene: it is a rare genetic autosomal dominant disease closely related to young adults generally presenting as a single parathyroid adenoma and bony lesion of the jaw. Some cases are associated with multiple renal hamartoma or diffuse cystic kidney disease. ${ }^{22,23}$ PHPT is rare in pregnancy and is frequently associated, if unknown and untreated, with the risk of fetal complication and abortion: another register-based retrospective cohort study demonstrates how diagnosis of PHPT does not seem to increase the risk of abortion neither birth weight, length or Apgar score. ${ }^{24}$ Neonatal primary hyperparathyroidism and familial hypocalciuric hypercalcemia are rare conditions caused by a defect in the gene coding for the calcium sensing receptor. In the first case newborns presented with hypotonia, poor feeding, constipation and respiratory distress: it is usually due to a homozygous mutation of calcium sensing receptor gene. ${ }^{25}$ Familial hypocalciuric hypercalcemia is generally a benign disorder caused by heterozygous inactivating mutation of calcium sensing receptor

Table 1. Pathologic and clinical condition related to primary hyperparathyroidism.

Pathological condition related to PHPT

Single adenomas

Hyperplasia and multiple adenomas

Carcinomas

Clinical condition related to PHPT

MEN type 1 and 2

Familial isolated hyperparathyroidism

Hyperparathyroidism-jaw tumor syndrome

Neonatal primary hyperparathyroidism

Hypocalciuric hyperkalemia

Hyperparathyroidism in pregnancy

PHPT, primary hyperparathyroidism; MEN type 1 and 2, multiple endocrine neoplasia type 1 and type 2 syndromes. gene: the patients presented with elevated serum calcium and PTH levels but not complication of primary hyperparathyroidism. ${ }^{26}$ The expression of the $V D R$ gene (vitamin D receptor) and the CASR gene (calcium sensing receptor) may play an important role in the development of PHPT caused by parathyroid adenomas: recent studies have explored the underlying molecular mechanism in the pathogenesis of sporadic symptomatic primary hyperparathyroidism implying a potential role in adenoma growth and differential clinical expression. ${ }^{27}$ PHPT is also described in patients who received radiation to the head and neck region: a cohort study among workers involved in the explosion of the Chernobyl Nuclear Station showed how about one fourth of patients analyzed, who had received an average dose of radiation ranging from 0.3 to $8.7 \mathrm{~Gy}$, developed PHPT: furthermore patients who received irradiation for benign situation in younger age are exposed to a major risk of PHPT. ${ }^{28,29}$ Radioactive iodine therapy has been suggested to cause PHPT: only small case series support this pathogenesis. The risk seems to be increased in elderly patients for whom it is strongly recommended serum calcium surveillance. ${ }^{30,31}$ Some genetic studies have recently demonstrated a correlation between over expressions of CCND1/PRAD1 oncogene for parathyroid sporadic tumor and an over expression of other genes like RET, MEN 1 and HRPT2 for sporadic and familial tumors miming PHPT: these over expressions can lead to cell cycle progression toward cell cycle phase promoting growth and cell division..$^{32}$ Some drugs like thiazide might unmask underling PHPT inducing an urinary reduction of calcium excretion: furthermore prolonged lithium therapy can also unmask a hyperparathyroidism status and can induce parathyroid iperplasia. ${ }^{33-36}$

\section{Diagnosis}

Diagnosis depends on the laboratory documentation of elevated serum calcium level often in conjunction with elevated serum PTH level. ${ }^{37,38}$

The differential diagnosis with other form of hypercalcemia is often complex and includes conditions related to metastatic cancer, multiple myeloma, sarcoidosis and other less common causes: the biochemical hallmark of PHPT is represented by the association of both elevated calcium levels and elevated or inappropriate PTH serum level. ${ }^{39}$ About $80-90 \%$ of patients presented with elevated PTH levels and low phosphorous level correlated with lower kidney resorption while the remaining $10-20 \%$ of patients had normal (inappropriate for the elevated calcium level) PTH levels: note that patients with hypercalcemia should have their PTH level suppressed and that the normal level is inappropriately high in these patients. ${ }^{40}$ PHPT is characterized by a shift in the set point for suppression of PTH 
secretion, such that the level of increased PTH secretion is inappropriate for the serum calcium level: finally the normal ability to suppress PTH in the presence of elevated calcium is lost. A low PTH level and high phosphorous level in hypercalcemic patients suggest that the hyperkalemia is not caused by PTH while a low PTH level with a low phosphorous level in hypercalcemic patients suggest the diagnosis of paraneoplastic hypercalcemia caused by parathyroid-related peptide. A low or normal PTH level in hypocalcemic patients suggests a state of hypoparathyroidism, provided the normal serum magnesium level: low magnesium levels inhibit release of PTH and mimic hypoparathyroidism. High PTH levels and low serum calcium in a patient with normal renal function suggest the presence of a resistance to action of PTH (pseudohypoparathyroidism). ${ }^{41}$ Regarding the analysis of PTH, the second and third generation assays measuring respectively the 1-84 primary amino acid sequence of PTH and other large fragment like the 7-84 truncated form, show a superior diagnostic sensitivity to other generation assays. ${ }^{42,43}$ Generally the measure of serum calcium should be adjusted and corrected for the albumin concentration of the patient being the ionized calcium level considered not useful in these patients: generally the correction is made by adding $0.8 \mathrm{mg} / \mathrm{dL}$ to the total calcium value for each $1 \mathrm{~g} / \mathrm{dL}$ below a referral concentration of albumin of $4 \mathrm{~g} / \mathrm{dL}{ }^{44,45}$ There are other clinical conditions that should be considered presenting with both calcium and PTH level elevated: one condition is represented by the chronic use of thiazide diuretics and lithium. If safe, when patients discontinued these drugs the elevated serum value of both calcium and PTH suggest an underling primary hyperparathyroidism. ${ }^{46-49} \mathrm{~A}$ rare clinical condition suggesting a primary hyperparathyroidism is represented by familial hypocalciuric hypercalcemia: these patients present moderate hypercalcemia and equivocal phosphate levels with mild elevation of PTH or (inappropriately) normal PTH levels. Measurement of $24 \mathrm{~h}$ urine calcium can detect lower value of calcium in the urine distinguishing familial hypocalciuric hypercalcemia from PHPT and MEN syndrome. This clinical condition is due to inactivating CASR mutation: the condition can be confirmed by CASR gene mutation screening. ${ }^{50}$ Paraneoplastic hypercalcemia due to the over production by tumor cells of PTH related protein can be distinguish from PHPT because this selected protein is not detected by the common assays used to detect PTH. ${ }^{51}$ Other uncommon clinical conditions presenting with hypercalcemia in the ambulatory setting, in which PTH level can also be elevated, are summarized in Table 2; aside from PHPT this condition can be easily differentiated however the diagnosis of hypercalcemia remains complex (Table 2) ${ }^{52}$ In order to obtain a clear differentiation with other clinical conditions measurement of PTH and serum cal- cium must be completed by renal function, measurement of 25 hydroxyvitamin $\mathrm{D}$, and serum phosphorous level. A renal ultrasound, to rule out nephrocalcinosis and nephrolitiasis, should be performed as soon as a bone mineral density (BMD) is obtained. Therefore markers of bone formation and resorption should be done (such as osteocalcin and bone-specific alkaline phosphatase) should be detected..$^{53}$

\section{Clinical features}

After the introduction of the routine screening for serum calcium, the diagnosis of PHPT has been increased. Today, when discovered, patients are generally asymptomatic: in the early stage symptoms are usually nonspecific like mild depression, weakness, anorexia, fatigue, constipation, polyuria and polydipsia. In the recent past some patients presented with bone disease and higher bone remodeling, with a reduction in BMD and increased risk of fracture; in the chronic phase symptoms from changes in genitourinary system are often present..$^{54-57}$

\section{Renal manifestation}

Renal complications remain the most challenging problem; usually symptoms related to nephrolitiasis and nephrocalcinosis occur in less than $10 \%$ of patients. Moreover nephrocalcinosis characterized by calcification within the renal parenchyma occurs in less than $5 \%$ of patients with PHPT and it is unusually associated with nephrolitiasis. ${ }^{58,59}$ Definitive renal changes occur in patients with nephrocalcinosis while patients with nephrolitiasis can be treated with extra corporeal shock wave lytotripsy. ${ }^{60,61}$

\section{Cardiovascular manifestation}

Cardiovascular manifestation includes arterial hypertension, coronary artery disease, left ventricular hy-

Table 2. Causes of hypercalcemia aside from primary hyperparathyroidism.

Metastatic cancer

Multiple myeloma

Sarcoidosis and other granulomatous disease

Ingestion of calcium or vitamin D

Familial hypocalciuric hyperkalemia

Lithium and thiazide diuretics

Milk-alkali syndrome

Paget disease

Pseudohyperparathyroidism 
pertrophy, valvular calcification and conduction abnormalities responsible of increased morbidity and mortality: in some series hypertension with associated clinical manifestation after parathyroid removal are responsible for elevated mortality rate..$^{62,63}$ There are few published data regarding cardiovascular manifestation as a consequence of PHPT. It is unclear if the effect of ventricular hypertrophy and diastolic dysfunction depends on the elevated value of PTH or it is due to the secondary effect of hypertension: the conclusion of all this low powered study suggests an increased all case mortality and fatal related cardiovascular disease. ${ }^{64}$ It remains uncertain whether parathyroidectomy decreases the risk of metabolic syndrome abnormalities associated with cardiovascular disease in patients with PHPT: a recent low powered study concludes that surgical treatment had no beneficial effect on cardiovascular risk, as assessed by the persistent insulin resistance and persistent symptoms of metabolic syndrome even after one year from successful parathyroidectomy. A more recent prospective case control study assessed the reversibility of symptoms after successful parathyroidectomy: that is still open to debate. ${ }^{65,66}$

\section{Skeletal manifestation}

In the past the early descriptions of patients with PHPT were related to those who had severe bone disease, condition known as osteitis fibrosa cystica: more recently the incidence of this disease is reported less than $1 \%$ while skeletal involvement characterized by a reduction of BMD affects approximately $25 \%$ of patients.$^{67} \mathrm{BMD}$ is generally altered at distal third radius (prevalence of cortical bone), minimally reduced at the lumbar spine (prevalence of spongious bone) and mildly altered at the femur (rate intermediate between cortical and spongious bone). ${ }^{68,69}$ Natural history of skeletal involvement in PHPT untreated patients remains unclear: in most series parathyroidectomy improves BMD. A recent review of patients with osteopenia and osteoporosis demonstrates an improvement of BMD in up to $75 \%$ of patients successfully treated by parathyroidectomy for primary PHPT. It also demonstrated that younger patients, and mostly those with severe skeletal symptoms of PHPT, may derive the most skeletal benefit from the surgical procedure. ${ }^{70,71}$ Two controlled clinical trials demonstrated, at a follow up of 24 months after parathyroidectomy, an improvement in BMD at the femoral neck and at the total hip but not at the lumbar spine. Another study demonstrated an increase in lumbar spine BMD but not hip or distal third of radius. ${ }^{72,73}$ Other retrospective studies investigated the risk of fracture in patients affected by PHPT. A case control study demonstrates a correlation between age, lumbar spine BMD and vertebral fracture with a strong correlation of BMD at the lumbar spine and PHPT: ${ }^{74}$ another retrospective cohort study demonstrates in multivariate analysis how parathyroidectomy was independently associated with decreased fracture risk. ${ }^{75}$ There are few studies comparing the effects of PHPT on the trabecular bone using different diagnostic tools in different skeleton sites such as micro computed tomography associated with bone biopsy or hystomorphometric studies. All patients with PHPT showed, at histomorphometric studies, an increased endosteal resorption while studies with microtomography showed an alteration of bone architecture in patients with severe PHPT. ${ }^{76,77}$

\section{Neuropsychiatric and neuromuscular manifestation}

Patients with PHPT may also present neuropsychiatric manifestations: psychiatric symptoms range from mild personality changes to severe depression, anxiety and psychosis. Other mild clinical presentations founded were represented by fatigue, paranoid state, memory loss and sleep disorder. The mechanism involved in the appearance of mental symptoms is not still clear as well as the prevalence of this abnormalities because of the few studies available and the lack of a rigorous evaluation: a recent case control study, evaluating neuropsychological symptoms and their improvement 6 months after surgical cure of PHPT, demonstrated that mild PHPT is associated with cognitive features affecting verbal memory but not verbal abstraction that, on the contrary, improves after parathyroidectomy ${ }^{78}$ Other recent studies evaluate the outcome of parathyroidectomy on psychiatric symptoms: a health survey study was conducted using parathyroid assessment of symptoms score (PAS) and short-form 36 health survey version 2.0 (SF-36v2) score in order to evaluate the outcome of parathyroidectomy on patients' psychiatric symptoms. The same study determined for a successful improvement of quality of life evaluated at the PAS and SF-36v2 score after surgical procedure. ${ }^{79}$ Another prospective case control study with matching pairs was conducted to determinate if surgical treatment could result in long lasting full recovery from neuropsychiatric symptoms: the successful parathyroid operation improved cognitive disorders. ${ }^{80}$ Other studies showed the improvement on neuromuscular symptoms after surgical parathyroidectomy: a recent evidence based on literature review of patient with PHPT, performed assessing symptoms and clinical condition associated with neuromuscular system, showed a benefit from operative cure although there are few level I randomized clinical trials addressing the benefit of parathyroidectomy in these patients. ${ }^{81}$ Further studies with strong level of evidence could better describe the peripheral nervous system involvement in PHPT. 


\section{Normocalcemic primary hyperparathyroidism}

Over the classical PHPT the normocalcemic form of PHPT (NPHPT) has been increasingly described since 1970: in this selected group of patients remains mandatory to exclude the causes of secondary hyperparathyroidism as well as vitamin D deficiency intake. It remains still unclear if NPHPT is an isolated form of disease or if it represents an evolution of classical PHPT in which the serum calcium, normal or mildly elevated in the first state of disease, increases progressively leading to the classical condition of hyperparathyroidism. ${ }^{82}$ A study conducted in patients seen for osteoporosis condition showed the occurrence of kidney stones in $28.6 \%$ of patients with NPHPT in contrast with only $0.7 \%$ of the not carriers demonstrating that NPHPT is not an indolent disease. ${ }^{83} \mathrm{~A}$ based longitudinal cohort study conducted over a population of patients seen in referred centers demonstrates that NPHPT patients have more skeletal involvement than patients with typical PHPT: this kind of patients, concludes the authors, may represent the earliest form of symptomatic PHPT rather than the asymptomatic form. ${ }^{84} \mathrm{~A}$ recent systematic search conducted by members of the Bone Metabolism Working Group of the Spanish Society of Endocrinology provides practical recommendations for the evaluation and follow up of patients with NPHPT: but it also concludes that there is just little evidence available about the clinical aspects and the clinical impact of this disease. More data are needed. ${ }^{85}$

\section{Imaging}

The aim of imaging is to localize the site of hyperfunctioning parathyroid tissue. In recent past most surgeons believed that localization techniques had to be reserved for patients undergoing re-exploration after a failed initial procedure: nowadays there are different modalities available that can be distinguished in functional imaging and anatomical imaging ${ }^{86}$ (Table 3).

\section{Sestamibi scans and $99 \mathrm{~m}$ Tc-pertechnetate subtraction scans}

Sestamibi, since its introduction in 1989, represents the technique of choice for nuclear localization studies: abnormal parathyroid glands have more mitochondria that sequester sestamibi (Figure 3). The uptake in the sestamibi scan closely depends on the size and weight of the parathyroid lesions: different techniques are used in order to clear differentiate parathyroid glands uptake and thyroid glands uptake. The technique well known as double phase technique is based on a more rapid wash out of sestamibi from thyroid tissue and not from pathological parathyroid glands: imaging is obtained after the administration of the radiopharmaceutical substance and $2 \mathrm{~h}$ later (Figure 4). The technique of subtraction imaging is performed by giving patients agents for thyroid imaging such as $99 \mathrm{~m}$ Tc-pertechnetate $(99 \mathrm{mTc})$ : thyroid images are definitively subtracted and remains only the parathyroid uptake. In

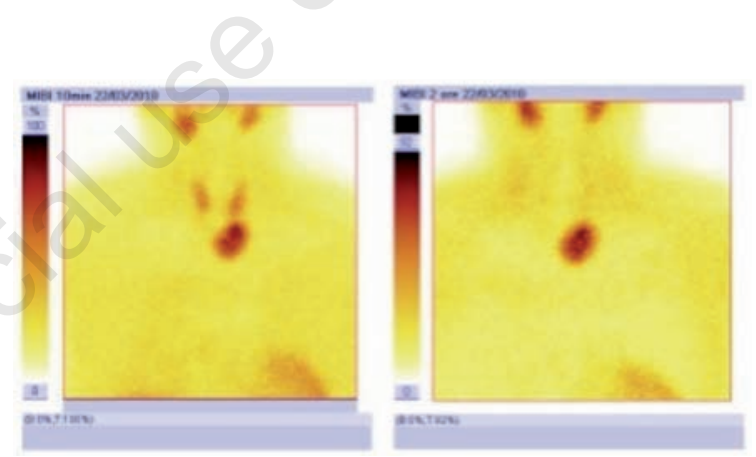

Figure 3. Initial and delayed sestamibi parathyroid scans: the image shows a left inferior parathyroid adenoma. Thyroid images were acquired from an anteroposterior view of the neck and upper part with patients in a supine position. The parathyroid scan was acquired $10 \mathrm{~min}$ (thyroid phase) and $\mathbf{1 2 0} \mathrm{min}$ (parathyroid phase) after intravenous administration of 15-20 mCI of 99mTcMIBI.

Table 3. Functional and anatomical imaging.

\begin{tabular}{lc}
\hline Functional & Anatomical \\
\hline Sestamibi scan (NI) & CT scan (NI) \\
\hline Conventional SPECT (NI) & MRI scan (NI) \\
\hline Sestamibi scan (NI) (with radioactive iodine or technetium) & Ultrasonography (with Doppler) (NI) \\
\hline $99 m$ me sestamibi scintigraphy with SPECT/CT (NI) & PET/PET CT (NI) \\
\hline
\end{tabular}

Angiography (I)

Selective venous essay (I)

US guided needle sample (I)

NI, non-invasive; CT, computed tomography; SPECT, single photon emission computed tomography; MRI, magnetic resonance imaging; PET, positron-emission tomography; I, invasive; US, ultrasound. 
case of parathyroid adenomas the technique reaches sensitivity of $80-90 \%$ in most series. ${ }^{87}$ In a recent series sestamibi showed positive results in $100 \%$ of patients with PHPT presenting with severe bone disease, $84 \%$ in the group of patients with renal involvement but not bone involvement and $64 \%$ in patients with initial asymptomatic PHPT. ${ }^{88}$ The addition of Computed tomography (CT) scan to the sestamibi double phase scan provides a three dimensional localization and is referred to the sestamibi single photon emission computed tomography (SPECT). The role of SPECT/CT for localization of parathyroid glands has been reported recently in literature for patients with previously untreated PHPT or to localize missing parathyroid glands in the neck or in the superior mediastinum. Literature results are variable: a recent pilot study found sensitivity and specificity in order of $46 \%$ and $100 \%$ for SPECT/CT in contrast with $92 \%$ and $100 \%$ respectively of positron emission tomography/CT (PET/CT) demonstrating a superior role of PET/CT. ${ }^{89,90}$ The role of sestamibi scintigraphy with SPECT/CT has been assessed in a recent single institution experience: authors conclude that sestamibi with SPECT procedure enables to identify a parathyroid adenoma in about two thirds of patients with PHPT and it allows surgeons to define an appropriate surgical plan..$^{91}$ The value of $99 \mathrm{~m} \mathrm{Tc}$ sestamibi SPECT/CT over conventional SPECT to identify or localize a parathyroid adenoma or hyperplasia has been recently evaluated in a retrospective study: the authors conclude that SPECT/TC has no significant value over conventional SPECT for identifying or locating a normally located parathyroid adenoma. ${ }^{92}$

\section{Ultrasonography}

In addition to functional imaging, anatomical localization imaging plays an important role in the identification of adenomas and gland hyperplasia: ultrasonography (US) (Figure 5) of the anterior neck is frequently used in conjunction with sestamibi scan obtaining a sensitivity of $97-100 \%$. When used alone it has the disadvantage of a limited resolving power and of being operator dependent; it can neither visualize ectopically located parathyroid glands nor glands located in the thyroid tissue: in this case the sensitivity reaches the value of $89 \%$ (with a range of $27-89 \%$ ) while specificity ranges from $87 \%$ to $94 \%$. US had the advantage of being cheaper, not exposing the patient to ionize radiation and it can be easily performed in the clinical setting. ${ }^{93}$ A recent risk adjusted analysis confirms that the addition of ultrasonography to scintigraphy based imaging test has an incremental value in localizing parathyroid adenoma and in decreasing the extent of surgery during parathyroidec-
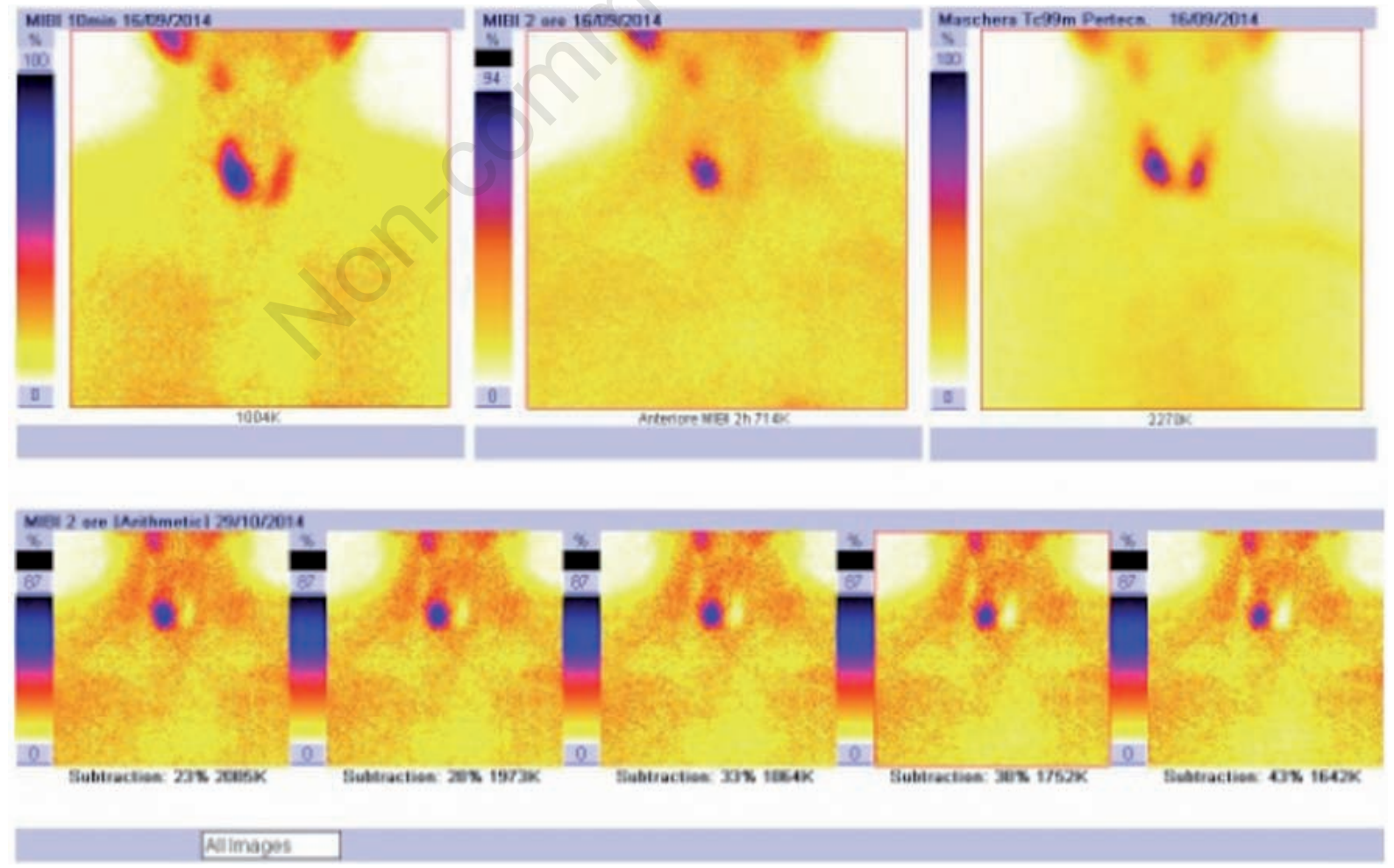

Figure 4. From top to bottom and from left to right sestamibi scan, delayed sestamibi and pertechnetate scans: the thyroid images are definitively subtracted remaining only the parathyroid uptake. 
tomy. ${ }^{94}$ It can be easily performed at the surgical table pre operatively by endocrine surgeon to direct the surgical incision prior of the exploration: parathyroid can appear typically from round to oval, homogeneous and hypoechoic compared with the thyroid gland and thyroid nodule: moreover parathyroid adenomas are often hypervascular at the Doppler flow. ${ }^{95}$

\section{Four-dimensional computed tomography and nuclear magnetic resonance}

Four-dimensional computed tomography (4D-CT) plays an important role in localizing pathological parathyroid tissue with high accuracy: in a recent retrospective study 4D-CT shows an accuracy of $93 \%$ in localizing a single pathological gland. In the presence of multiglandular disease the sensitivity was much lower falling to $44 \%$ but specificity was $100 \% .{ }^{96}$ The evaluation of accuracy of 4D-CT scan as an emerging technique in localization and lateralization of abnormal parathyroid glands in patients with PHPT was recently assessed in a prospective study conducted at a tertiary referral center: the authors conclude that it can be used in any case of PHPT ensuring a high resolution contrast enhancement localization of pathological parathyroid glands and it can be used for planning minimally invasive parathyroidectomy versus bilateral neck exploration. ${ }^{97}$

Nuclear magnetic resonance (MRI) has recently been evaluated for the preoperative localization of hyperfunctioning parathyroid glands: a prospective study showed how MRI has a better sensitivity and positive predictive value than $99 \mathrm{mTc}$ sestamibi scintigraphy for the detection of hyperfunctioning parathyroid glands. The addition of the two localizing imaging provides an additional increase in sensitivity and positive predictive value reducing the extension of the surgical procedure. ${ }^{98}$ A comparative study of preoperative imaging methods in patient with PHPT compares the accuracy rates achieved in US, 99mTc sestamibi, SPECT and MRI: the authors conclude that the com- bination of US and sestamibi as imaging methods for preoperative localization of parathyroid adenoma or multiglandular hyperplasia often produces the best and satisfactory results. ${ }^{99}$ The invasive localizing study such as angiography or venous PTH sampling lacked interest because the non-invasive procedures are most used and report high success rate. Some authors suggest the use of venous sampling when imaging is in favor of an ectopic mediastinal gland or a deep cervical adenoma, and in case of persistent or recurrent PHPT after failed surgery with negative neck exploration or PHPT well diagnosed but in the presence of negative imaging. ${ }^{100}$

\section{Surgical treatment}

The main treatment for patients affected by PHPT is surgery: the general agreement declares that surgery is properly indicated for patients with symptomatic disease such as renal and bone diseases or instead for patients with cardiovascular and psychiatric dysfunction. Asymptomatic patients who present incidentally elevated calcium and PTH level, according to the Fourth International Workshop, have to be enrolled for surgery in case of serum calcium concentration $1.0 \mathrm{mg} / \mathrm{dL}$ above upper limit of normal, $24 \mathrm{~h}$ urinary calcium excretion $>400 \mathrm{mg}$, creatinine clearance reduced by $30 \%$, BMD T score less than -2.5 standard deviation at any site and age minor than 50 years old. ${ }^{101,102}$ The Expert Panel concludes that surgical approach to parathyroidectomy should be suggested for patients with PHPT who meet the above-reported criteria: the current guidelines pointed out that patients who do not reach this criteria may be enrolled for surgical procedure if there is an appropriate consensus in multidisciplinary meeting held by surgeons and endocrinologists. ${ }^{103,104}$ In regard to the surgical procedure, patients should be carefully counselled about the risk of recurrent nerve injury, major bleeding and hypocalcemia: the consensus should be focused on the

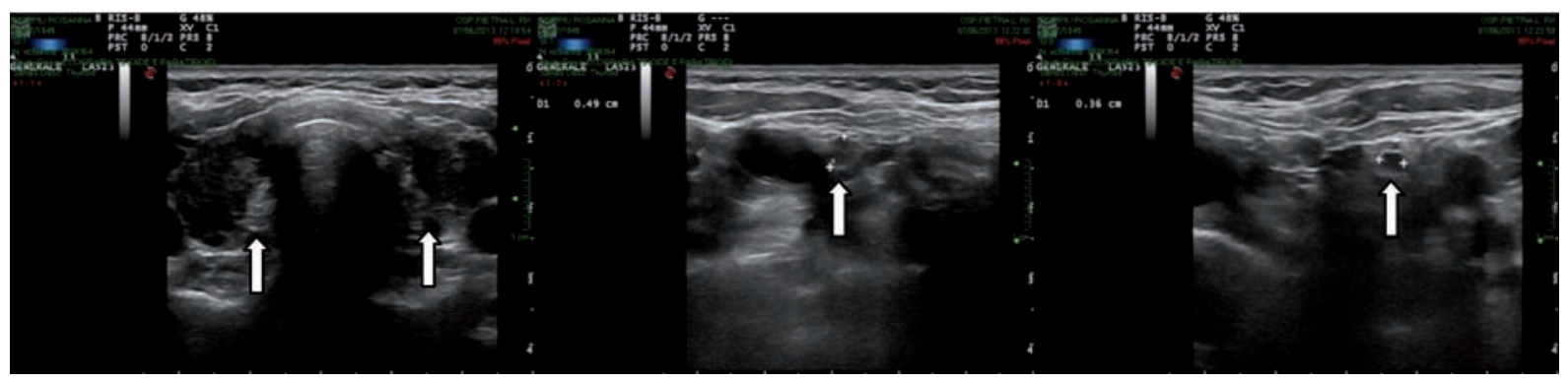

Figure 5. Ultrasonography images of bilateral parathyroid adenoma (left). Right inferior and left inferior parathyroid glands (arrows) show an irregular and poorly marginated border. Right inferior parathyroid adenoma (middle): largest diameter $0.49 \mathrm{~cm}$. Left inferior parathyroid adenoma (right): largest diameter $0.36 \mathrm{~cm}$. 
chance of converting the approach from a focused mini invasive procedure to a four gland exploration. In selected case, surgery could be unpredictable without success and could require more than one exploring procedure. The surgical procedure can be performed in general anesthesia: the ultimate focused minimal invasive procedure could also be performed with local anesthesia or with local control with anesthetic block in particular in high risk patients not suitable for intubation. ${ }^{105,106}$ Curative rates in patients undergoing parathyroidectomy range from $95 \%$ to $98 \%$ when surgery is done in a high volume center headed by a high volume surgeon: the complication rates are unusual and literature reports percentage inferior to $3 \%$ for all injuries. Mini invasive procedure in experienced skilled hand may be associated with lower morbidity and general costs. ${ }^{107}$ Standard procedure consists in bilateral neck exploration with direct visualization of all abnormal parathyroid and at least one normal parathyroid. The four gland exploration procedure in experienced hand, a gold standard procedure 20 years ago, has a successful rate of over 95\%: moreover it is usually done when preoperative procedure of standard localization fails in localizing a parathyroid adenoma, in a presumptive state of multiglandular disease, in case of re-operation or in those centers in which surgeon cannot use standard preoperative localization assay. ${ }^{108,109}$ All surgeons, experts in focused parathyroidectomy, must have the necessary familiarity with bilateral neck exploration because sometimes focused localizing techniques and the same PTH intra operative measurement could fail in localizing an offending parathyroid. On the other side focused parathyroidectomy plays an important role when preoperative localization techniques successfully identify the affected gland and there is a correct way to predict the curative value of the surgical procedure. When a single offending gland is preoperative localized, combining functional and anatomical imaging, a unilateral neck exploration could be done in order to remove the single offending gland. The surgeon performs a smaller incision (2-4 cm long) near to the putative preoperative localization and removes the affected gland identifying both parathyroid gland (pathological and normal unilateral) and the course of recurrent laryngeal nerve. ${ }^{110}$ In this case intra operative measurement of PTH serum level gives the surgeon the certainty of having removed the pathological gland responsible for PHPT. ${ }^{111}$ Recent technological developments, including the option of intra operative measurement of PTH, endoscopic technique and mainly the utilization of intra operative gamma probe, justify the success of minimally invasive surgical procedures. ${ }^{112-114}$ The mini invasive procedures are summarized in Table 4. Different techniques have been described: some surgical techniques include the insufflations of gas in the neck in order to create an operative surgical field allowing incision distant from the affected gland, or alternatively introducing an endoscope in a small incision, dissecting structure with dedicate mini surgical instruments. In patients with a history of keloid or hypertrophic scar formation sometimes cosmetic results may be not satisfactory: furthermore because of the presence of glands located in the mediastinum a thoracotomy procedure is needed. In this case the robotic assisted parathyroidectomy approach, either transaxillary or transthoracic, may play an important role. ${ }^{115}$ The initial experience demonstrates that this technique is safe, feasible and effective in the treatment of PHPT as obtained by a recent retrospective review of medical charts. ${ }^{116} \mathrm{~A}$ prospective randomized blinded trial published in 2006 concludes that both minimally invasive video assisted parathyroidectomy (MIVAP) and open minimally invasive parathyroidectomy (OMIP) offer a valuable approach to solitary parathyroid adenoma with minimal morbidity and excellent results in terms of successful rate. MIVAP presents advantages in terms of recognition of the recurrent laryngeal nerve, lower score of pain and need for drugs, a shorter scar and a higher satisfaction cosmetics rate. ${ }^{117}$ Total endoscopic approach (the so-called lateral approach parathyroidectomy by Henry) is not routinely performed: a recent paper concludes that it can be proposed in experienced hand in more than half of PHPT patients obtaining good immediate results. Conversion rate remains higher and it may explain the low widespread of this specialized technique. ${ }^{118}$ Minimally invasive radio guided parathyroidectomy technique consists in giving patient $99 \mathrm{mTc}$ sestamibi on the day of surgical procedure and it undergoes imaging for the functional localization of the affected gland: a small incision is then done on the putative site and a gamma camera pen is used to guide the surgeon to the gland in a technique similar to those used for sentinel node biopsy. The skin incision is usually $2-3 \mathrm{~cm}$ long when a single gland exploration is performed. ${ }^{119}$ We found few prospective well designed studies comparing conventional parathyroidectomy and minimally invasive procedure: the difference consists in cost and operative time being

Table 4. Mini invasive procedure for primary hyperparathyroidism.

\begin{tabular}{ll}
\hline Acronym & Procedure \\
\hline OMIP & Open minimally invasive parathyroidectomy \\
\hline MI-RP & Minimally invasive radio guided parathyroidectomy \\
\hline MIVAP & Minimally invasive video assisted parathyroidectomy \\
\hline EP & Endoscopic parathyroidectomy (purely) \\
\hline RAP & $\begin{array}{l}\text { Robotic assisted parathyroidectomy (transaxillary } \\
\text { gasless approach) }\end{array}$ \\
\hline
\end{tabular}


complication rate or cure rate the same. ${ }^{120} \mathrm{~A}$ prospective randomized trial compares MIP with conventional parathyroidectomy: there was no difference in curative rate and operative time. The MIP group had low pain scale, lower analgesic consumption and greater cosmetic satisfaction at 1 month and 6 months after surgery. After one year from the surgical procedure there were no differences in cosmetic and aesthetic satisfaction: MIP was very expensive. ${ }^{121}$ Another prospective study shows the same results in terms of curative rate for both MIP and conventional procedure: MIP procedure shows a shorter operative time while calcium levels remain lower in the first four operative days in the group who undergoes the conventional procedure. ${ }^{122}$ Patients with persistent or recurrent hyperparathyroidism after initial surgery still remain difficult to treat. There is more than one cause of failed first treatment: an inexperienced surgeon, the multiple gland disease, an ectopic gland, supernumerary gland, parathyromatosis from spillage after the initial surgical procedure. ${ }^{123}$ Patient should undergo a complete functional and anatomical localization study: particular attention should be paid to the anterior mediastinum and thorax. The approach needs to be multidisciplinary with a correct planning of the surgical procedure made by the team leader - frequently the surgeon - engaging endocrinologist, nuclear medicine physician, radiologist and pathologist both clinical and laboratory. ${ }^{124,125}$

\section{Role of intraoperative measurement of serum parathyroid hormone level}

Intraoperative PTH (IOPTH) serum level monitoring has been increasingly used during mini invasive procedure for PHPT: PTH levels are usually measured at the beginning of surgery procedure and ten minutes after the removal of the offended gland. It usually takes 15-20 min for the results: many high volume centers have the necessary equipment directly in the operative room. If there is a drop in the PTH serum level major than $50 \%$ of the pre resection measurement that means that the source of PHPT has been removed: otherwise persistent disease may be suspected. ${ }^{126}$ A systematic review on the diagnosis and treatment of PHPT conducted between 1995 and 2003 which analyzed more than 200 published series in which IOHPT was routinely used concludes that a focused unilateral approach was completed as intended in $94.5 \%$ of cases of PHPT while there was a conversion rate to a bilateral neck exploration in $5.5 \%$ of cases: persistent hypercalcemia including all cases in which IOPTH was used was $1.3 \%$. ${ }^{127}$ Some recent studies suggest the use of IOPTH only in selected patients in order to minimize procedure costs, optimize the time of surgery and relative operative room occupation: a recent prospective study includes all patients in a protocol of preoperative localization of a parathyroid abnormal gland by using $99 \mathrm{mTc}$ sestamibi and US neck study. Only patients with US positive results being the functional result of $99 \mathrm{~m}$ TC sestamibi negative underwent serum IOPTH measurement. All patients with positive localization (both functional and anatomic) were offered for mini invasive procedure obtaining a successful rate of $99 \%$. Seventy percent of patients who presented with positive ultrasound and negative sestamibi underwent mini invasive procedure with IOPTH and had an inadequate fall of IOPTH data highly predictive of multiglandular disease: in all cases the use of IOPTH obviously increases cost, length of operative time and operative room occupation. ${ }^{128}$ There are some recent published criteria for IOPTH monitoring focusing on the timing of sample measuring: these authors include a serum sample during the surgical manipulation of the offended gland supposing that the true beginning of the PTH decay origins from the clamping or manipulation of the gland. Authors conclude that the advantages of this criterion are both the prompt recognition of false negative results and the construction of a decay curve necessary to support the surgeon during the excision of the offended gland. ${ }^{129}$ Challenging patients with negative sestamibi scan and discordant imaging studies were recently evaluated in a prospective study: the authors divide patients into three groups. Group A sestamibi positive and ultrasound positive, Group B sestamibi positive and ultrasound negative and Group $\mathrm{C}$ sestamibi and ultrasound negative. The overall operative success using IOPTH was $99.12 \%$ in Group A, 98\% in Group B, and $90.91 \%$ in Group C. IOPTH changes the operative management in $2.63 \%$ of patients in Group A and $14 \%$ in Group B. ${ }^{130}$ In a large multicenter Scandinavian study, including more than 2000 patients, imaging preoperative procedure consisting on sestamibi scan and US was done in 1831 patients, while IOPTH was done in 792 patients. Surgeons performed unilateral exploration in $22 \%$ of cases, focused parathyroidectomy in $17 \%$ of cases and bilateral neck exploration in $2 \%$ of cases. The use of IOPTH measurement increased the curative rate and decreased the risk of postoperative hypocalcemia when associated with preoperative localization imaging. ${ }^{131}$ In case of multiglandular disease the IOPTH assay during minimally invasive parathyroidectomy may be helpful in the detection of double adenomas, minimizing the risk of recurrent operations and facilitating cost-effective minimally invasive surgery. ${ }^{132}$

\section{Medical treatment}

Drugs for PHPT can be divided into two groups: antiresorptive drugs inhibiting increased born turnover which can be further divided into estrogen like com- 
pounds (estrogen, oral contraceptives, selected estrogen receptor inhibitor) bisphosphonates and calcitonin and finally drugs that interfer with PTH secretion (only cinacalcet). ${ }^{133}$ Medical treatment remains indicated for those patients who present a severe contraindication for surgical therapy, patients in which surgery failed or patients with no current criteria for surgical treatment: the US Food and Drug Administration confirms that surgery is the only definitive cure. ${ }^{134}$

\section{Cinacalcet hydrocloride}

Calciomimetic drugs as cinacalcet hydrochloride provide the first effective medical treatment because they bind the calcium sensing receptor, reducing both serum calcium and parathyroid hormone level: the drug is generally well tolerated with common side effects generally dose-related like nausea and headache. ${ }^{135,136}$ A recent study conducted on a group of patients treated with cinacalcet confirms that medication was well tolerated ( $83.4 \%$ of patients) with more common adverse events being represented by nausea and vomiting. Cinacalcet rapidly reduced serum calcium level and the reduction remained stable after 1 year of treatment: furthermore they observed a reduction in PTH serum level. The study concludes that cinacalcet is an effective and attractive alternative in non-surgical patients and it may also help clinician in preoperative hypercalcemia management. ${ }^{137} \mathrm{~A}$ post marketing experience on the management of cinacalcet in patients affected by PHPT was conducted collecting data from 135 patients treated in eight Italian centers between October 2008 and March 2011 [following the approval by the European Medical Agency (EMA)]. Retrospective data collected regard 100 patients with sporadic PHPT and 35 patients with familial PHPT: cinacalcet effectively reduced serum calcium levels, in fact the majority of patients became normocalcemic $(65 \%$ of patients with sporadic form and $80 \%$ of patients with familial form). ${ }^{138}$ A multicenter study conducted over 48 patients with PHPT treated with cinacalcet demonstrated a normalization of serum calcium concentration in $73 \%$ of patients: the PTH level remains elevated and decreased in only $7.6 \%$ of cases in the same period of observation. Long term observation of this group of patients over 5 years demonstrated a maintenance of normal serum calcium level in approximately $80 \%$ of patients: mean serum PTH level decreased progressively maintaining stable results over the observation period. ${ }^{139}$

\section{Hormone replacement therapy}

Estrogens used at high dose reduce the serum calcium level, but they do not reduce the parathyroid hormone level, all this demonstrates the predominant effect on bone resorption rather than on PTH secre- tion: estrogen containing compounds may be less attractive because of the potential risk of breast cancer, cardiovascular disease and thromboembolism. About oral contraceptives no data had already showed the ability in preventing fractures in general population and no data are nowadays available about their effect on women affected by PHPT. The role of estrogen replacement therapy for patients who decide against surgery or who are not candidates to surgical procedure has been recently described in a literature review: the discussion about the role of estrogen therapy replacement rules on a series of randomized clinical trials. A historical randomized double blind placebo controlled trial conducted on postmenopausal women affected by PHPT over two years evaluated the association between estrogen and medroxiprogesterone versus placebo: data were assessed including BMD and biochemical markers of bone turnover. ${ }^{140}$ All biochemical markers of bone turnover (alkaline phosphatase activity, urinary excretion of hydroxyproline and urinary calcium excretion), progressively decreased at the natural end of the study. On the other side BMD increased significantly in total body. At the extension of the study for 4 years all the effects were maintained. ${ }^{141}$

\section{Bisphosphonates}

Multiple data from randomized controlled study demonstrate the role of oral alendronate on bone turnover and BMD. A double blind randomized single cross over trial on the role of alendronate $10 \mathrm{mg}$ daily was conducted in men affected by primary hyperparathyroidism in comparison with women in postmenopausal state: alendronate significantly increased BMD at 12 months and it was associated with a reduction in bone turnover in men. These data, similar in postmenopausal women, suggested the value of alendronate to prevent skeletal damage in men: the authors conclude that future studies are needed to confirm protection against the risk of fracture in both male and female population. ${ }^{142}$ Another randomized multicenter double bind placebo controlled trial over forty-four patients treated with oral alendronate was associated with progressive increase of BMD when compared with the base line and progressive decrease of bone turnover maintained over two years of observation period. After 1 year patients who received placebo started with the same therapy demonstrating the same results in BMD and bone turnover. ${ }^{143} \mathrm{~A}$ recent prospective study was conducted to compare the efficacy of alendronate and raloxifene over twentyfour postmenopausal women with osteoporosis and diagnosis of PHPT: patients were randomized in two groups (an alendronate group - 12 patients - and a raloxifene group - 12 patients). Control group consists of ten patients not suitable for surgery. Both medicaments improved bone density in the lumbar area but 
the most significant decrease in serum calcium levels was observed in the alendronate group compared to raloxifene and control group: these data suggest the usefulness of alendronate in the short term control of calcium levels in patients awaiting for surgery. ${ }^{144}$

The efficacy of alendronate associated with cinacalcet has been retrospectively investigated in patients with primary hyperparathyroidism: twenty tree patients were enrolled. Ten patients received cinacalcet associated with alendronate and 13 patients received cinacalcet in monotherapy. There was no difference in the rate of PTH and serum calcium decrease in the two groups: the T-score increased significantly at the lumbar spine and femur in patients treated with alendronate plus cinacalcet while it remains unchanged in the mono therapy group. BMD improved in patients receiving the two drugs associated rather than in patients receiving cinacalcet alone. ${ }^{145}$

\section{Conclusions}

PHPT remains a challenging disease with multiple profiles in which no classical manifestation like decrease of quality of life, fatigue and depression play an emerging role in the literature debates: the successful treatment must occur in the context of a multidisciplinary team were endocrine surgeon, endocrinologist, radiologist and nuclear medicine perform the best treatment. Diagnosis revolves around routine measurement of serum calcium associated with a high or inappropriate serum PTH levels: the differential diagnosis with other form of hypercalcemia is often complex and includes condition related to metastatic cancer, multiple myeloma, sarcoidosis and other less common causes. The aim of imaging is to localize the site of hyperfunctioning parathyroid tissue: nowadays there are different modalities available that can be distinguished between functional imaging and anatomical imaging. The definitive treatment for PHPT remains parathyroidectomy: medical treatment could be an alternative in patients not candidates to surgical procedure or refusing surgery. Cinacalcet, estrogen and biphosphonates play an important role in controlling serum calcium level, increasing BMD and decreasing the risk of fracture.

\section{References}

1. Fukuma S, Kurita N, Fukagawa M, et al. Impact of cinacalcetintroduction on MBD management: the MBD5D study in Japan. Kidney Int Suppl 2013;3:436-41.

2. Stuart HC, Harvey A, Pasieka JL. Normocalcemic hyperparathyroidism: preoperatively a disease, postoperatively cured? Am J Surg 2014;207:673-80.

3. Eufrasino CS, Holanda NC, Prazeres PA, et al. Epidemiology of primary hyperarathyiroidism and its non-clas- sical manifestation in the city of Recife, Brazil. Endocr Rev 2012;33:SUN-336.

4. Tassone F, Gianotti L, Baffoni C, et al. Prevalence and characteristics of metabolic syndrome in primary hyperparathyroidism. J Endocrinol Invest 2012;35:841-6.

5. Cusano NE, Wang P, Cremers S, et al. Asymptomatic normocalcemic primary hyperparathyroidism: characterization of a new phenotype of normocalcemic primary hyperparathyroidism. J Bone Miner Res 2011; 26:S290.

6. Macfarlane DP, Yu N, Leese GP. Subclinical and asymptomatic parathyroiddisease: implications of emerging data. Lancet Diabetes Endocrinol 2013;1:329-40.

7. Golden SH, Robinson KA, Saldhana I, et al. Clinical review: prevalence and incidence of endocrine and metabolic disorders in the United States: a comprehensive review. J Clin Endocr Metabol 2009;94:1853-78.

8. Lindner G, Felber R, Schwarz C, et al. Hypercalcemia in the ED: prevalence, etiology, and outcome. Am J Emerg Med 2013;31:657-60.

9. Silin H, Lundgren E, Malminn H, et al. Prevalence of primary hyperparathyroidism and impact on bone mineral density in elderly men: MrOs Sweden. World J Surg 2011;35:1266-72.

10. Clarke BL. Epidemiology of primary hyperparathyroidism. J Clin Densitom 2013;16:8-13.

11. Press DM, Siperstein AE, Berber E, et al. The prevalence of undiagnosed and unrecognized primaryhyperparathyroidism: a population-based analysis from the electronic medical record. Surgery 2013;154:1232-7.

12. Minisola S. Primary hyperparathyroidism is one of the three most frequent endocrine disorders, typically diagnosed in the years following menopause and with advancing age. J Endocrinol Invest 2012;35:1.

13. Eufrazino C, Veras A, Bandeira F. Epidemiology of primary hyperparathyroidism and its non-classical manifestations in the city of Recife, Brazil. Clin Med Insights Endocrinol Diabetes 2013;6:69-74.

14. Marques TF, Vasconcelos R, Diniz E, et al. Normocalcemic primary hyperparathyroidism in clinical practice: an indolent condition or a silent threat? Arq Bras Endocrinol Metabol 2011;55:314-7.

15. Yu N, Donnan PT, Fynn RW, et al. Increased mortality and morbidity in mild primary hyperparathyroid patients. The parathyroid epidemiology and audit research study (PEARS). Clin Endocrinol 2010;73:30-4.

16. Schneider DF, Mazeh H, Chen H, et al. Predictors of recurrence in primary hyperparathyroidism: an analysis of 1386 cases. Ann Surg 2014;259:563-8.

17. Yu N, Donna PT, Murphy MG, et al. Epidemiology of primary hyperparathyroidism in Tayside, Scotland, UK. Clin Endocrinol 2009;71:485-93.

18. Yeh MW, Ituarte PH, Zhou HC, et al. Incidence and prevalence of primary hyperparathyroidism in a racially mixed population. J Clin Endocrinol Metab 2013;98: 1122-9.

19. Vierimaa O, Viallablanca A, Aimov A, et al. Mutation analysis of Men 1, HRPT2, CASR, CDKN 1B and AIP genes in primary hyperparathyroidism patients with features of genetic predisposition. J Endocrinol Invest 2009;32:512-8.

20. Catani F, Pardi E, Ambrogini E, et al. Genetic analysis in familial isolated hyperparathyroidism: implication for 
clinical assessment and surgical management. Clin Endocrinol (Oxf) 2006;64:146-52.

21. Horiuchi K, Okamoto T, Iihara M, et al. Analysis of genotype-phenotype correlations and survival outcomes in patients with primary hyperparathyroidism caused by multiple endocrine neoplasia type 1: the experience at a single institution. Surg Today 2013;43:894-9.

22. Mizusawa N, Uchino S, Iwata T, et al. Genetic analysis in patients with familial isolated hyperparathyroidism and hyperparathyroidism-jaw tumor syndrome. Clin Endocrinol (Oxf) 2006;65:9-16.

23. Misiorowski W, Zgliczyński W. Prevalence of primary hyperparathyroidism among patients with low bone mass. Adv Med Sci 2012;57:308-13.

24. Abood A, Vestergaard P. Pregnancy outcome in women with primary hyperparathyroidism. Eur J Endocr 2014; 171:69-76.

25. Varshney S, Bhadada SK, Saikia UN, et al. Simultaneous expression analysis of Vitamin D receptor, calcium sensing receptor, cyclin D1, and PTH in symptomatic primary hyperparathyroidism in Asian Indians. Eur J Endocrinol 2013;169:109-16.

26. Obermannova B, Banghova K, Sumnik Z, et al. Unusually severe phenothype of neonatal primary hyperparathyroidism due to a heterozygous inactivating mutation in the CASR gene. Eur J Pediatr 2009;168: 569-73.

27. Tonyushkina KN, O'Connor S, Dunbar NS. A novel CaSR mutation presenting as a severe case of neonatal familial hypocalciuric hypercalcelmia. Int J Pediatr Endocrinol 2012;1:13.

28. Boehm BO, Rosinger S, Belyi D, et al. The parathyroid as a target for radiation damage. New Engl J Med 2011;365:676-8

29. Wilson SD, Doffek KM, Wang TS, et al. Primary hyperparathyroidism with a history of head and neck irradiation: the consequences of associated thyroid tumors. Surgery 2011;150:869-77.

30. Colaco SM, Si M, Reiff E, et al. Hyperathyroidism after radioactive iodine therapy. Am J Surg 2007;194:323-7.

31. Guven A, Salman S, Boztepe H, et al. Parathyroid changes after high dose radioactive iodine in patients with thyroid cancer. Ann Nucl Med 2009;19:451-7.

32. Sharretts JM, Simonds WF. Clinical and molecular genetics of parathyroid neoplasm. Best Pract Rec Clin Endcorinol Metabol 2010;24:491-502.

33. Wermes RA, Kearns AE, Jenkins GD, et al. Incidence and clinical spectrum of thiazide associated hypercalcemia. Am J Med 2007;120:911.

34. Endres DB. Investigastion of hypercalcemia. Clin Biochem 2012;45:954-63.

35. Nair GC, Menon R, Jacob P, et al. Lithium induced parathyroid disfunction: a new case. Indian $\mathrm{J}$ Endocrol Metabol 2013;17:930-32.

36. McKnight RF, Adida M, Budge K, et al. Lithium toxicity: a systematic review and meta-analysis. Lancet 2012;379:721-8

37. Crowley R, Gittoes N. How to approach hypercalcemia. Clin Med 2013;13:287-90.

38. Bilezkian JP, Silverberg SJ. Clinical practice. Asymtpomatic primary hyperparathyroidism. New Engl J Med 2004;350:1746-51.

39. Prasarttong-Osoth P, Whatanaoran P, Imrutaicharoen- choke W, et al. Primary hyperparathyroidism: 11 year experience in a single institute in Thailand. Int J Endocrinol 2012;2012:952426.

40. Wallace LB, Parikh RT, Ross LV, et al. The phenotype of primary hyperparathyroidism with normal parathyroid hormone levels: how low can parathyroid hormone go? Surgery 2011;150:1102-12.

41. Fritchie K, Zedek D, Grenache DG. The clinical utility of parathyroid hormone-related peptide in the assessment of hypercalcemia. Clin Chim Acta 2009;402:146-9.

42. Suliburk JW, Perrier ND. Primary hyperparathyroidism. Oncologist 2007;12:644-53.

43. Gruson D, Lepoutre T, Ahn SA, et al. Comparison of the Elecsys PTH (1-84) assay with four contemporary second generation intact PTH assays and association with other biomarkers in chronic kidney disease patients. Clin Biochem 2013;46:781-6.

44. Marangella M. PTH measurement: where do we stand? G Ital Nefrol 2009;26:600-7.

45. Salinas M, Lopez-Garrigos M, Pomares F, et al. Serum calcium (S-Ca), the forgotten test: preliminary results of an appropriateness strategy to detect primary hyperparathyroidism (pHPT). Bone 2013;56:73-6.

46. Labriola L, Wallemacq P, Gulbis B, et al. The impact of the assay for measuring albumin on corrected ("adjusted") calcium concentrations. Nephrol Dial Transplant 2009;24:1834-8.

47. McKnight RF, Adida M, Budge K, et al. Lithium toxicity profile: a systematic review and meta analysis. Lancet 2012;379:721-8.

48. Saunders SB, Saunders EF, Gauger PG. Lithium therapy and hyperparathyroidism: an evidence based assessment. World J Surg 2009;33:2314-23.

49. Desai HV, Gandhi K, Sharma M, et al. Thiazide-induced severe hypercalcelmia: a case report and literature review. Am J Ther 2010;17:234-6.

50. Shinall MC, Dahir KM, Broome JT. Differentiating familial hypocalciuric hipercalcemia from primary hyperparathyroidism. Endocr Pract 2013;19:697-702.

51. Valdes-Socin H, Niaourou V, Vandeva S, et al. Paraneoplastic endocrine syndromes: diagnosis and management. Rev Med Suisse 2009;5:1668-74.

52. Wermers RA, Kearns AE, Jenkins GD, et al. Incidence and clinical spectrum of thiazide-associated hypercalcemia. Am J Med 2007;120:911.

53. Lumachi F, Motta R, Cecchin D, et al. Calcium metabolism and hypercalcemia in adults. Curr Med Chem 2011;18:3529-36.

54. Koumakis E, Souberbielle JC, Payet J, et al. Individual site-specific bone mineral density gain in normocalcemic primary hyperparathyroidism. Osteoporosis Int 2014;25:1963-8.

55. Paunovic I, Zivaljevic V, Stojanic R, et al. Primary hyperparathyroidism in children and young adults: a single institution experience. Acta Chir Belg 2013;113:35-9.

56. Shah VN, Bhadada SK, Bhansali A, et al. Influence of age and gender on presentation of symptomatic primary hyperparathyroidism. J Psotagrad Med 2012;58:107-11.

57. Carnevale V, Romagnoli E, Pipino M, et al. Primary hyperparathyroidism. Clin Ter 2005;156:211-26.

58. Cassibba S, Pellegrino M, Gianotti L, et al. Silent renal stones in primary hyperparthyroidism: prevalence and clinical features. Endocr Pract 2014;16:1-16. 
59. Corbetta S, Baccarelli A, Aroldi A, et al. Risk factors associated to kidney stones in primary hyperparathyroidism. J Endocrinol Invest 2005;28:122-8.

60. Lila AR, Srathi V, Jagtap V, et al. Renal manifestation of primary hyperparathyroidism. Indian J Endocrinol Metab 2012;16:258-62.

61. Rejnmark L, Vestergaard P, Mosekilde L. Nephrolitiasis and renal calcification in primary hyperparathyroidism. J Endocrinol Metabol 2011;96:2377-85.

62. Tassone F, Gianotti L, Baffoni C, et al. Prevalnce and charachteristics of metabolic syndrome in primary hyperparathyroidism. J Endocrinol Invest 2012;35:841-6.

63. Luboshitzky R, Chertok-Schaham Y, Lavi I, et al. cardiovascular risk factors in primary hyperparathyroidism. J Endocrinol Invest 2009;32:317-21.

64. Baykan M, Erem C, Erdogan T, et al. Assessment of left ventricular diastolic function and the Tei index by tissue doppler imaging in patients with primary hyperparathyroidism. Clin Endocrinol 2007;66:483-8.

65. Agarwal G, Nanda G, Kapoor K, et al. Cardiovascualr disfunction in symptomatica primary hyperparathyroidism and its reversal after curative parathyroidectomy: results of a prospective case control study. Surgery 2013;154:1394-403.

66. Ishay A, Herer P, Luboshitzky R. Effects of successful parathyroidectomy on metabolic cardiovascular risk factors in patients with severe primary hyperparathyroidism. Endocr Pract 2011;17:584-90.

67. Bandeira F, Cusano NE, Silva BC, et al. Bone disease in primary hyperparathyroidism. Arq Bras Endocr Metabol 2014;58:553-61.

68. Mosekilde L. Primary hyperparathyroidism and the skeleton. Clin Endocrinol 2008;69:1-19.

69. Lewiecki EM, Miler PD. Skeletal effects of primary hyperparathyroidism: bone mineral density and fracture risk. J Clin Densitom 2013;16:28-32.

70. Vu TD, Wang XF, Wang Q, et al. New insight into the effects of primary hyperparathyroidism on the cortical and trabecular compartments of bone. Bone 2013;55:57-63.

71. Dy BM, Grant CS, Wermers RA, et al. Changes in bone mineral density after surgical intervention for primary hyperparathyiroidism. Surgery 2012;152:1051-8.

72. Tamura Y, Araki A, Chiba Y, et al. Remarkable increase in lumbar spine bone mineral density and amelioration in biochemical markers of bone turnover after parathyroidectomy in elederly patients with primary hyperparathyiroidism: a 5-year follow up study. J Bone Mineral Metabol 2007;25:226-31.

73. Rao DS, Philips ER, Divin GW, et al. Randomized controlled clinical trial of surgery versus no surgery in patients with mild asymptomatic primary hyperparathyroidism. J Clin Endocr Metabol 2004;89:5415-22.

74. Vignali E, Viccica G, Diacinti D, et al. Morphometric vertebral fractures in postmenopausal women with primary hyperparathyiroidism. J Clin Endocrinol Metabol 2009;94:2306-12.

75. VandeWalde LH, Liu IL, Haigh PI. Effect of bone mineral density and parathyroidectomy on fracture risk in primary hyperparathyroidism. World J Surg 2009;33:406-11.

76. Kulak CA, Dempster DW. Bone histomorphometry: a coincise review for endocrinologist and clinicians. Arq Bras Endocr Metabol 2010;54:87-98.

77. Dempster DW, Muller R, Zhou H, et al. Preserved three- dimensional cancellous bone structure in mild primary hyperparathyiroidism. Bone 2007;41:19-24.

78. Walker MD, McMahon DJ, Inabnet WB, et al. Neuropsychological features in primary hyperparathyroidism: a prospective study. J Clin Endocrinol Metabol 2009; 92:1951-8.

79. Remakant P, Verma AK, Chand G, et al. Saltuary effect of parathyroidectomy on neuropsychiatric symptoms in patients with primary hyperparathyroidism: evaluation using PAS and SF-36v2 scoring system. J Postgrad Med 2011;57:96-101.

80. Dotzenrath CM, Kaestch AK, Pfingsten H, et al. Nuropsychiatric and cognitive changes after surgery for primary hyperparathyroidism. World J Surg 2006;30: 680-5.

81. Caron NR, Pasieka JL. What symptoms improvement can be expected after the operation for primary hyperparathyroidism?. World J Surg 2009;33:2244-55.

82. Bileziakian JP, Silverberg SJ. Normocalcemic primary hyperparathyiroidism. Arq Bra Endocrinol Metabol 2010;54:106-9.

83. Marques TF, Vasconcelos R, Diniz E, et al. Normocalcemic primary hyperparathyroidism: an indolent condition or a silent threat? Arq Bras Endocrinol Metabol 2011;55;314-17.

84. Lowe H, McMahon DJ, Rubin MR, et al. Normocalcemic primary hyperparathyroidism: further characterization of a new clinical phenotype. J Clin Endocrinol Metabol 2007;92:3001-5.

85. Martinez Diaz-Guerra G, Jodar Gimeno E, Reyes Garcia $\mathrm{R}$, et al. Normocalcemic primary hyperparathyroidism: recommendations for management and follow up. Endocrinol Nutr 2013;60:456.

86. Gopalakrishna Iyer N, Ashoc R Shaha. Current concepts in the management of primary hyperparathyroidism. Indian J Surgical Oncol 2010;1:112-9.

87. Bandeira Fa, Oliveira RI, Griz LH, et al. Difference in accuracy of TC $99 \mathrm{~m}$ - sestamibi scanning between severe and mild form of primary hyperparathyroidism. J Nucl Med Technol 2008;36:30-5.

88. Khorasani N, Mohammadi A. Effective factors on the sensitivity of preoperative sestamibi scanning for primary hyperparathyroidism. Int J Clin Exp Med 2014;15: 2639-44.

89. Van Hoom Ra, Vriens D, Postema JW, et al. The influence of SPECT reconstruction algorithms on image quality and dagnostic accuracy in phantom measurement and $99 \mathrm{mTc}$ sestamibi parathyroid scintigraphy. Nucl Med Commun 2014;35:64-72.

90. Lezaic L, Rep S, Sever MJ, et al. 18F-Fluorocholine $\mathrm{PET} / \mathrm{TC}$ for ocalization of hyperfunctioning parathyroid in primary hyperprathyroidims: a pilot study. Eur J Nucl Med Mol Imaging 2014 [Epub ahead of print].

91. Ciappuccini R, Morera J, Pascal P, et al. Dual-phase 99mTc sestamibi scintigraphy wih neck and thorax SPECT/CT in primary hyperparathyroidism: a single institution experience. Clin Nucl Med 2014;37:223-8.

92. Gayed IW, Kim EE, Broussard WF, et al. The value of $99 \mathrm{mTc}$ - sestamibi SPECT/TC over conventional SPECT in the evaluation of parathyroid adenomas or hyperplasia. J Nucl Med 2005;46:248-52.

93. Chien D. Jacene H. Imaging of parathyroid glands. Otholaryngol Clin North Am 2010;43:399-415. 
94. Tee MC, Chan SK, Nguyen V, et al. Incremental value and clinical impact of neck sonography for primary hyperparathyroidism: a risk adjusted analysis. Can J Surg 2013;56:325-31.

95. Shenk WG 3rd, Hanks JB, Smith PW. Surgeon-perfomed ultrasound for primary hyperparathyroidism. Am Surg 2013;79:681-5.

96. Chazen JL, Gupta A, Dunning A, et al. Diagnostic accuracy of 4D-CT for parathyroid adenomas and hyperplasia. Am J Neuroradiol 2012;33:429-33.

97. Kelly HR, Hamberg LM, Hunter GJ. 4D-CT for preoperative localization of abnormal parathyroid glands in patients with primary hyperparathyroidism: accuracy and ability to stratify patients by unilateral versus bilateral disease in surgery-naïve and re-exploration patents. ANJR J Neuroradiol 2014;35:176-81.

98. Michlel L, Dupont M, Rosiere A, et al. The rationale to performing MR imaging before surgery for primary hyperparathyroidism. Acta Chir Belg 2013;113:112-22.

99. Akbaba G, Berker D, Isik S, et al. A comparative study of pre-operative imaging methods in patients with primary hyperparathyroidism: ultrasonography $99 \mathrm{mTc}$ sestamibi, single photon emission computed tomography and magnetic resonance imaging. J Endcorinol Invest 2012;35:359-64.

100. Fulla Y, Bonnichon P, Tisier F, et al. Biology of primary hyperparathyroidism: selective venous sampling. J Radiol 2009;90:413-21.

101. Udelsman R, Arkestrom G, Biagini C, et al. The surgical management of asymptomatic primary hyperparathyroidism: proceeding of the fourth international workshop. J Clin Endocrinol Metabol 2014 [Epub ahead of print].

102. Silverberg SJ, Clarke BL, Peacock M, et al. Current issue in the presentation of asymptomatic primary hyperparathyroidism: proceeding of the fourth international workshop. J Clin Endocrinol Metabol 2014 [Epub ahead of print].

103. Marcocci C, Bollerslev J, Khan AA, et al. Medical management of primary hyperparathyroridism: proceeding of the fourth international workshop. J Clin Endocrinol Metabol 2014 [Epub ahead of print].

104. Bilezikian JP, Brandi ML, Eastell R, et al. Guidelines for the management of asymptomatic primary hyperparathyroidism: summary statement from the fourth international workshop. J Endcrinol Metabol 2014 [Epub ahead of print].

105. Melo C, Pinhero S, Carvalho L, et al. Identification of parathyroid glands; anatomical study and surgical implication Surg Radiol Anat 2014 [Epub ahead of print].

106. Mohebati A, Shaha R. Anatomy of thyroid and parathyroid glands and neurovascular relation. Clin Anat 2012;25:19-31.

107. Stavrakis AL, Ituarte PH, Ko CY, et al. Surgeon volume as a predictor of outcomes in inpatient and outpatient endocrine surgery. Surgery 2007;142:887-99.

108. Augustine MM, Bravo PE, Zeiger MA. Surgical treatment of primary hyperparathyroidism. Endocr Pract 2011;17:75-82.

109. Pelizzo MR, Pagetta C, Piotto A, et al. Surgical treatment of primary hyperparathyroidism: from bilateral neck exploration to minimally invasive surgery. Minerva Endocrinol 2008;33:8593.
110. Udelsman R, Lin Z, Donovan P. The superiority of minimally invasive parathyroidectomy based on 1650 consecutive patents with primary hyperparathyroidism. Anna Surg 2011;253:585-91.

111. Harrison BJ, Triponez F. Intraoperative adjuncts in surgery for primary hyperparathyroidism. Langenbecks Arch Surg 2009;394:799-809.

112. Henry JF, Thakur A. Minimal access surgery: thyroid and parathyroid. Indian J Surg 2010;1:200-6.

113. Cassinello N, Ortega J, Liedo S. Intraoperative realtime $(99 \mathrm{~m}) \mathrm{TC}$ sestamibi scintigraphy with miniature gamma camera allows minimally invasive parathyroidectomy without ioPTH determination in primary hyperparathyroidism. Langenbecks Arch Surg 2009; 394:869-74.

114. Caudle AS, Brier SE, Calvo BF, et al. Experienced radio-guided surgery teams can successfully perform minimally invasive radio-guided parathyroidectomy without intraoperative parathyroid hormone assays. Am Surg 2006;72:785-9.

115. Karagkounis G, Uzun DD, Mason DP, et al. Robotic surgery for primary hyperparathyroidism. Surg Endosc 2014;28:2702-7.

116. Noureldine SI, Lewing N, Tufano RP, et al. The role of the robotic-assisted transaxillary gasless approach for the removal of parathyroid adenomas. ORL J Otorhinolaryngol Relat Spec 2014;76:19-24.

117. Barczynski M, Cichon S, Konturek A, et al. Minimally invasive video-assisted parathyroidectomy versus open minimally invasive parathyroidectomy for a solitary parathyroid adenoma: a prospective, randomized, blinded trial. World J Surg 2006;30:721-31.

118. Forquet T, Germain A, Zarnegar R, et al. Totally endoscopic lateral parathyroidectomy: prospective evaluation of 200 patients. ESES 2010 Vienna presentation. Langenbecks Arch Surg 2010;395:935-40.

119. Lee WJ, Ruda J, Stack BC Jr. Minimally invasive parathyroidectomy using intraoperative sestamibi localization. Otolaryngol Clin North Am 2004;37:789-98.

120. Russel CF, Dolan SJ, Laird JD, et al. Randomaized clinical trial comparing scan-directed unilateral versus bilateral cervical exploration for primary hyperparathyroidism due to solitary adenoma. Br J Surg 2006;93:418-21.

121. Slepavicius A, Beisa V, Janusonis V, et al. Focused versus conventional parathyroidectomy for primary hyperparathyroidism: a prospective, randomized, blinded trial. Langenbecks Arch Surg 2008;393:659-66.

122. Bergenfelz A, Kanngieser V, Zielke A, et al. Conventional bilateral cervical exploration versus open minimally invasive parathyroidectomy under local anaesthesia for primary hyperparathyroidism. Br J Surg 2005;92:190-7

123. Twight BA, Van Dalen T, Vroonhoven TJ et al. Recurrent hyperparathyroidism caused by benign neoplastic seeding: two cases of parathyromatosis and a review of the literature. Acta Chir Belg 2013;113:228-32.

124. Arnalsteen L, Quievreux JL, Huglo D, et al. Reoperation for persistent or recurrent primary hyperparathyroidism. Seventy-seven cases among 1888 operated patients. Ann Chir 2004;129:224-31.

125. Karakas E, Müller HH, Schlosshauer T, et al. Reoperation for primary hyperparathyroidism: improvement of outcome over two decades. Langenbecks Arch Surg 2013;398:99-106. 
126. Hathaway TD, Jones G, Stechman M, et al. The value of intraoperative PTH measurement in patients with mild hyperparathyroidism. Langenbecks Arch Surg 2013;398:723-7.

127. Ruda JM, Hollenbeack CS, Stack BC, et al. A systematic review of the diagnosis and treatment of primary hyperparathyroidism from 1995 to 2003 . Otolaryngol Head Neck Surg 2005;132:359-72.

128. Hwang RS, Morris LF, Ro K, et al. A selective, Bayesan approach to intraoperative PTH monitoring. Ann Surg 2010;251:1122-6.

129. Locchi F, Cavalli T, Giudici F, et al. Intraoperative PTH monitoring: a new approach based on the identification of the "true" time origin of the decay curve. Endocr J 2014;61:239-47.

130. Calò PG, Pisano G, Loi G, et al. Surgery for primary hyperparathyroidism in patients with pre operatively negative sestamibi scan and discordant imaging studies: the usefulness of intraoperative parathyroid hormone monitoring. Clin Med Insights Endocrinol Diabetes 2013;6:63-7.

131. Bergenfelz AO, Jansson SK, Wallin GK, et al. Impact of modern techniques on short-term outcome after surgery for primary hyperparathyroidism: a multicenter study comprising 2708 patients. Langenbecks Arch Surg 2009;394:851-60.

132. Ypsilantis E, Charfare H, Wassif WS. Intraoperative PTH assays during minimally invasive parathyroidectomy may be helpful in the detection of double adenomas and may minimize the risk of recurrent surgery. Int J Endocrinol 2010;2010:178671.

133. Vestergaard P. Current pharmacological options for the management of primary hyperparathyroidism. Drugs 2006;66:2189-211.

134. Bollerslev J, Marcocci C, Sosa M, et al. Current evidence of reccomandation for surgery, medical treatment and Vitamin D repletion in mild primary hyperparathyroidism. Eur J Endocrinol 2011;165:851-64.

135. Peacock M, Bolognese MA, Borofsky $M$, et al. Cinacalcet treatment of primary hyperparthyiroidims: biochemical and and bone densitometria outcomes in a 5 years study. J Clin Endocrinol Metabol 2009;94: 4860-7.

136. Marcocci C, Chanson P, Shoback D, et al. Cinacalcet reduces serum calcium concentration in patients with intractable primary hyperparthyroidims. J Clin Endocrinol Metab 2009;94:2766-72.

137. Lique-Fernandez I, Garcia-Martin A, Lique-Pazos A. Experience with cinacalcet in primary hyperprathyroidims: results after 1 year of treatment. Ther Adv Endocrinol Metabol 2013;4:77-81.

138. Saponaro F, Faggiano A, Grimaldi F, et al. Cinacalcet in the management of primary hyperparathyroidism: post marketing experience ofan Italian multicenter group. Clin Endocrinol 2013;79:20-6.

139. Peacock M, Bilezikian JP, Klassen PS, et al. Cinacalcet hydrochloride maintains long term normocalcemia in patients with primary hyperparathyroidism. J Clin Endocrinol Metabol 2005;90:135-41.

140. Carnevale V, Romagnoli E, Pipino M, et al. Primary hyperparathyroidism. Clin Ther 2005;156:211-26.

141. Farford B, Presutti RJ, Moragna TJ, et al. Non surgical management of primary hyperparathyroidism. Mayo Clin Proc 2007;82:351-5.

142. Khaan AA, Bilezikian JP, Kung A, et al. Aledronate therapy in men with primary hyperparathyroidism. Endocr Pract 2009;15:705-13.

143. Khan AA, Bilezikian JP, Kung AW, et al. Alenodronate in primary hyperprathyroidism: a double-blind, randomized, placebo-controlled trial. J Clin Endocrinol Metab 2004;89:319-25.

144. Akbaba G, Isik S, Ates Tutuncu Y, et al. Comparison of alendronate and raloxifene for the management of primary hyperparathyroidism. J Endocrinol Invest 2013; 36:1076-82.

145. Faggiano A, Di Somma C, Ramundo V, et al. Cinacalcet hydrocloride in combination with alendornate normalizes hypercalcemia and improves bone mineral density in patients with primary hyperparathyroidism. Endcorine 2011;39:283-7. 